\title{
Collagen: Applications of a Natural Polymer in Regenerative Medicine
}

\author{
Umber Cheema, Michael Ananta and Vivek Mudera \\ UCL Division of Surgery \& Interventional Science, \\ Institute of Orthopaedics \& Musculoskeletal Science, \\ Stanmore Campus, Brockley Hill,

\section{Introduction}

Collagen is a naturally occurring matrix polymer which is highly conserved across species. It is the predominant extra-cellular matrix component of most connective tissues within the mammalian body, comprising one third of all protein found within tissues. Collagens are extracellular and have a mainly structural role. Critical parameters including density, packing and orientation (or direction) results in distinctively varying mechanical properties in tissues such as bone, skin, tendon and cartilage.

In connective tissue lost to trauma or disease, replacement tissue strategies, have to consider mechanical implications. Synthetic polymers can be designed to have the mechanical integrity of the native structure to be replaced but eventually this will be degraded and replaced by the host. The major target protein that will be replaced in connective tissues is collagen. The other alternative is to start with collagen as a natural polymer substrate and tailor its mechanical properties in vitro. Given the critical role this protein plays in tissue structure there have been and continue to be efforts into extracting this protein, reforming 3D scaffolds for tissue engineering as well as controlling density and direction parameters to form tissues in vitro. The main difference in the building of bulk tissues is the cell-rich or matrix-rich nature of the tissue being engineered. Where the matrix dominates a tissue, the mechanical properties of the matrix are critical, i.e in connective tissue. In tendon for example, the alignment of collagen fibrils along the principle axis of strain application, and the nature of a 'dual' size of fibril diameters, provides incredible strength to this tissue. Compared directly to a tissue like dermis, where collagen is interlocked in a basket-weave formation with elastin to provide tensile strength in multiple axis to ensure stretching of this tissue does not compromise its integrity. Thus, when engineering tissues in vitro, technologies and processing to control parameters of collagen architecture have been developed to mimic those found in tissues in situ. This field of controlled processing is growing, as the sophistication of methods employed to create biomimetic scaffolds advances.

Type I collagen scaffolds are widely used in clinical practice and the collagen for these materials are generally obtained either from cultured cells or extracted from native tissues. Extraction encompasses the entire range from decellularisation of collageneous tissues preserving the native architecture to the complete break down into collagen molecules which can later be reconstituted into their native fibrillar structure. One of the most common 
collagen scaffolds in clinical use is de-cellularised dermal tissue. By decellularising an entire piece of connective tissue, the immunogenicity of the tissue is removed whilst retaining the collagen architecture and other matrix components in the native form. These scaffolds induce and guide tissue repair when implanted in a full-thickness skin defect as a template for dermal regeneration. Methods to enhance the in vivo persistence of such decellurarised scaffolds, involve dispersion of the collagen matrix. The dispersion of collagen can result in the degradation of the collagen into polymers, oligomers or monomers dependent upon the treatment methods applied. This is followed by co-precipition with a glycosaminoglycan. In these cases the inherent architecture of the native tissue is lost and reformed in vitro.

The formation of living collagenous tissue equivalents rely upon the cell seeding of decellularised native tissues or cell-seeding into prefabricated, porous collagen scaffolds. The next generation of skin equivalents are bio-engineered cell based technologies using cell produced collagen. These include the next generation bilayered skin equivalents produced by Organogenesis. The use of solubilised collagen as dermal and lip fillers for the correction of contour deformaties, is a growing cosmetic procedure. This relies upon collagen dispersion from either human cadaver or bovine tissue, which can then be stably re-injected to 'plump' to fill minor defects. The question is whether the fibrosis response by the injection of these products causes the therapeutic effect or the products themselves.

The main focus of this chapter is to address the importance of collagen protein structure and its relation to normal mechanical function in matrix-rich tissues. This chapter will overview the established, clinically used and new novel processing technologies being researched to improve and control bulk collagen processing for applications in regenerative medicine, and new directions needed to control collagen architecture.

\section{Collagen- the dominant extra-cellular protein}

Collagen is a naturally occurring matrix polymer which is well conserved across species. It is the predominant extra-cellular matrix component of most connective tissues within the mammalian body, comprising one third of all protein found within tissues, particularly musculo-skeletal tissues. There are 27 known types of Collagen which are extracellular and have a mainly structural role. The configuration of this protein greatly affects its role in tissue architecture. Parameters including density, packing, degree of cross-linking and orientation (direction) result in distinctively varying mechanical properties in tissues such as bone, skin, tendon and cartilage.

An example is the bi-modal distribution of fibril diameters found in tendons, which are aligned parallel to the direction in which strain is applied (Morgan et al. 2006). This confers strength in one direction, which is precisely the axis of strain generation required for a tendon.In comparison to this, the collagen architecture of skin varies considerably. Collagen fibrils in this tissue are weaved in to a more 'random' structure, along with components like elastin, to confer a 'stretchy' property on this tissue, which is constantly being deformed due to the structure and function of skin. In fact, parallel alignment of collagen fibrils is more apparent in scarred skin tissue compared to normal (Verhaegen et al. 2009). The architecture of this protein is, therefore, tissue-specific, and mimicking this architecture will be important for scaffolds design and tissue engineering.

Although Collagen is the major extra-cellular component of most connective tissues in the body, additional ECM components contribute to the mechanical properties, cell-attachment properties and regulation of architecture. An example of this is the presence of collagen II in 
conjunction with proteoglycans in cartilage, which provide compressive load strength to this tissue. Although mainly collagen type I, Hydroxyapatite is the major mineral component of bone. There is currently active research in making composite matrices containing both of these components, to create biomimetic scaffolds for bone engineering. For the tissue engineering of vascular grafts, the elasticity of vascular structures (such as the pulmonary aorta) is critical to mimic in vitro. This mechanical feature is dependent upon the very high presence of elastin within these structures, and for vascular graft engineering the incorporation of elastin protein, along with the other component proteins is necessary. Vessels contain multiple cell types and specific basement membrane proteins are necessary for the correct phenotype of these cells, particularly endothelial cells, which line the lumen. One of the most successful approaches for tissue engineering remains de-cellularisaiton of xenograft tissue, followed by cell-seeding using bioreactor culture.

\section{Matrix-rich tissues}

The matrix component of different tissue types is dependent upon whether these tissues are cell-rich (central nervous system, skeletal muscle, organs like heart, liver, kidneys), versus matrix-rich (tendon, ligament, cartilage and bone). Collagen type I plays an important role in most matrix rich tissues, but there are numerous other protein components critical to the unique architecture of tissues.

Matrix-rich tissues are often very hierarchical in structure, because the physical nature of the tissue is mainly as a support system for the skeleton. Both tendon and skeletal muscle have distinct 'bundle within a bundle' structure, where mainly collagen (in the case of tendon) and myofibrils (in the case of skeletal muscle) are bundled in graduating structures, along the principal axis of strain the tissue will have to bear. The packing of protein components thus becomes critical to how load is distributed within a tissue, and ultimately results in whether a tissues is a successful component for locomotion.

The architecture of collagen type I is particularly crucial to matrix-rich tissues, as the strength required of these tissues can only really be achieved by recapitulating these precise features, including orientation of fibrils (direction), diameter and density. If we take bone as an example, this tissue is intrinsically linked to the skeletal muscle system, and itself through connections with tendons and ligaments. It is mainly composed of collagen type I and a mineral component. The conformation of collagen varies dependent on which bone we study, and where we study it. The most common 'surface' feature of bone is composed of alternate lamellae of longitudinal and transverse bundles of collagen fibres, running parallel to the surface of the bone (Smith 1960). The mineral component within bone is interspersed within these lamellae structures. The intense load endured by bone tissue is therefore appropriated by the particular structure of the extra-cellular components. As bone is subject to load in varying axis of strain, a simple parallel bundled array of fires (as seen in tendon) is not observed.

Whilst engineering specific tissues, mimicking the correct matrix components as well as the specific architecture will result in increased success in modeling of a tissue. Functionality of any engineered tissue is likely to be critically dependent on the biomimicry, particularly of the structure of the protein component. For replacement of matrix-rich tissues, the mechanical functionality of any tissue engineered scaffold will be optimal if the architecture and packing of the matrix components closely mimics that found in vivo naturally. Collagen to collagen attachment is primarily through increased cross-linking, and cell-collagen 
interaction is primarily through the integrins a1 $\beta 1$ and $\alpha 2 \beta 1$. The majority of replacement tissues engineered implants and constructs currently either rely upon synthetic grafts, which provide the adequate mechanical load-bearing properties, or on compositions of native proteins which do not necessarily provide the appropriate mechanical properties.

\section{Collagen used in vivo}

The majority of collagen scaffolds used for clinical purposes are made from extracting collagen from tissues. In the process of extraction very often collagen and other proteins are highly denatured. This is a result of the highly effective methods of cross-linking in vivo. The limited understanding of the protein Elastin, for example, is mainly due to our inability to extract it in its native form from tissues. The efficient mechanism by which proteins are built into tissue architectures by the body are in part hindering our complete understanding of those very mechanisms and proteins.

The main use of collagen for clinical application are as replacement scaffolds used as tissue fillers, and as support matrices for matrix rich tissues. These collagen scaffolds are now widely used in clinical practice, primarily as skin substitutes and dermal fillers. Because of the naturally high composition of collagen in matrix rich tissues, collagen scaffolds are the natural protein to use as a scaffold, however in the process of engineering or assembling such scaffolds, much of the native protein structure, and thus inevitably function, is lost.

The extraction method varies for each scaffold type and resulting scaffolds properties therefore vary. The majority of these scaffolds are composite materials, often with synthetic components, primarily to provide strength to the scaffold, necessary to hold sutures and withstand the mechanical loads at the implant site and/or tissue. Here, we overview the products available as collagen type I based tissue equivalents and substitutes.

\subsection{Collagen dermal tissue equivalents}

The most widely used tissue equivalent scaffolds clinically, is for replacement dermal equivalents. The majority of products available rely upon a fabricated collagen mesh, mainly without a cellular component. Generally collagen is isolated from tissue samples, and in the process the collagen is greatly disaggregated and denatured, often resulting in complete loss of the original architecture and packing, and comprising mainly of fragments of the original protein. The majority of these scaffold equivalents are composed solely of collagen, without the addition of other extracellular matrix components.

Integra (Yannas et al. 1981)is the first FDA-approved skin substitute consisting of a suturable, semi-permeable silicone elastomer (polysiloxane, Dow Corning Liquid Silastic Medical Adhesive Type A) cured to an underlying dermal component made of a degradable crosslinked (vacuum dehydration and gluteraldehyde) coprecipitation of bovine collagen and $(8 \%)$ chondroitin 6-sulfate (a shark cartilage derived glycosaminoglycan). Integra is used to reconstruct the skin in a two stage procedure in surgically excised burn injuries (Burke et al. 1981;Heimbach et al. 1988) or in excised benign or malignant lesions (Prystowsky et al. 2001). After it has integrated, generally 2-3 weeks after implantation the silicone membrane is removed and the neodermis is grafted with a split thickness skin graft. Histologically the dermal matrix disappears after one month (Stern et al. 1990) and only elicits a small transient immune response (Michaeli and McPherson 1990). Graft take is similar to allografts, but not as good as autografts. One of the major benefits being is that it is cosmetically superior over meshed autografts (Heimbach, Luterman, Burke, Cram, 
Herndon, Hunt, Jordan, McManus, Solem, Warden, \& . 1988) and the reconstructed skin has elastic properties matching that of normal skin (Nguyen et al. 2010).

Alloderm (LifeCell Corp, Branchburg, NJ) is decellularised dermal matrix derived from human cadaver skin by the tonic removal of epidermis with $\mathrm{NaCl}$ and decellularisation with sodium dodecyl sulphate (a detergent) of the dermal component. For storage, the resultant acellular dermal matrix was freeze-dried in a cryoprotectant solution (dextran, sucrose, raffinose) followed by a two-step drying procedure. For use the dermal matrix is rehydrated in two changes of sterile normal saline. Clinical studies have shown it to be useful as a dermal substitute in full thickness burns without signs of rejection, showing revascularisation, cellular repopulation, incorporation into the wound and cosmetic results similar to intermediate thickness skin grafts (Wainwright et al. 1996).

Dermagraft (Cooper et al. 1991) is fabricated by seeding and maintaining fibroblasts on a Vicryl mesh for a period of 2 to 3 weeks to achieve a sufficient amount of tissue formation for a therapeutic effect. The product is currently FDA approved for the treatment of venous (Omar et al. 2004), neuropathic and diabetic ulcers (Marston et al. 2003). Dermagraft is more effective than conventional treatments of chronic (persisting longer than 6 months) venous (Omar, Mavor, Jones, \& Homer-Vanniasinkam 2004), neuropathic and diabetic ulcers (Marston, Hanft, Norwood, \& Pollak 2003) and the product is FDA-approved for these applications. The material 'takes' in (immune-compromised) animal wounds, but integration in human (immuno-competent) subjects has not been reported and Dermagraft requires multiple applications to achieve a clinical effect.

Dermagraft is not to be confused with Dermagraft-TC (Dermagraft Transient Cover, currently marketed as TransCyte) which is fabricated by culturing allogeneic human neonatal fibroblasts 17 days on Biobrane (Bertek Pharmaceuticals Inc., WV, USA) a semipermeable polymer (silicone) membrane with partially embedded woven monofilament nylon mesh onto which porcine collagen peptides are chemically bound to form a hydrophilic surface (Hansbrough et al. 1994). The product is devitalised by freezing and the cell produced ECM contains fibronectin, type I collagen, proteoglycans and growth factors. The product is a temporary cover for partial thickness burns and is spontaneously ejected by healing wounds. It has shown to, decrease hospital stay compared to conventional treatment (silvazine) (Amani et al. 2006), prevent frequent and painful dressing changes, autografting, and decreases the time to wound closure compared to alternative treatments (Biobrane alone, silvazine) (Kumar et al. 2004).

Apligraf (Organogenesis Inc., MA and Novartis Pharmaceutical Corp., NJ, US) (Wilkins et al. 1994) is a commercially available skin equivalent consisting of a bovine collagen (type I) hydrogel seeded with allogeneic human neonatal foreskin fibroblasts and keratinocytes (Bell et al. 1981a;Bell et al. 1981b). The mechanical properties of the dermal component are improved by allowing collagen to contract for 6 days after which keratinocytes are seeded and cultured for 4 days under submerged conditions and terminally differentiated into a stratified epidermis for an additional 7 days at the air/liquid interface. Apligraf is currently FDA approved for the treatment of venous leg (Falanga 2005) and diabetic foot ulcers (Veves et al. 2001). Apligraf is more effective than conventional treatment (i.e. compression therapy and saline-moistened gauze, respectively) in achieving wound closure in chronic (lasting longer than 6 months) non-healing venous leg (Falanga 2005) and diabetic foot ulcers (Veves, Falanga, Armstrong, \& Sabolinski 2001) and is FDA-approved for the treatment of these conditions. As previously mentioned, Apligraf does not persist in human acute full thickness skin defects (cells remain in the wound up to 4 weeks) (Griffiths et al. 
2004) and requires multiple applications for it to be effective. It is noteworthy that Organogenesis is currently in late stage development of a next generation allogeneic skin equivalent, VCTO1, which similar to Apligraf with the only difference being that the dermal matrix will be human fibroblast derived making its components all human.

OrCel (Forticell Bioscience, Inc., formerly Ortec International, Inc., NY, US) (Eisenberg and Llewelyn 1998) is currently under investigation for the treatment of chronic wounds. The product is currently FDA-approved for the treatment of split-thickness skin graft donor sites (Still et al. 2003) and for use in the surgical release of hand syndactyly secondary to epidermolysis bullosa. This commercially available skin equivalent is fabricated by seeding allogeneic fibroblasts into a preformed lyophilised bovine collagen (type I) sponge which is cultured for 2 days, inverted and seeded with keratinocytes on its non-porous side and cultured for an additional 7-14 days (Bell, Ehrlich, Sher, Merrill, Sarber, Hull, Nakatsuji, Church, \& Buttle 1981b)to form a confluent monolayer epidermis.

\subsection{Dermal fillers}

\section{Bovine collagen}

Zyderm I, introduced in 1977 (Knapp et al. 1977) and FDA approved in 1981, is an injectable soluble, bovine collagen implant for the treatment of fine, superficial lines. The acid-soluble collagen is extracted from bovine dermal tissue with acetic-acid and is then pepsin-treated to yield telopeptide-poor collagen with low antigenicity. The collagen is $96 \%$ type I and $4 \%$ type III collagen and it is purified to over $99 \%$ and dispersed in phosphate buffered saline (PBS) containing $0.3 \%$ lidocaine hydrochloride to a concentration of $35 \mathrm{mg} / \mathrm{ml}$. The monomeric collagen solution spontaneously polymerises at $37^{\circ} \mathrm{C}$ (Knapp, Luck, \& Daniels 1977). Zyderm II, FDA approved in 1983, is similar to Zyderm I but contains $65 \mathrm{mg} / \mathrm{ml}$ of collagen and is used to treat mild to moderate lines. Both Zyderm I and II only provide a short clinical effect from two to three months (Kligman and Armstrong 1986). Zyplast, FDA approved in 1985, is similar to Zyderm I collagen, but is chemically cross-linked with $0.0075 \%$ glutaraldehyde, making it less susceptible to degradation by collagenases (McPherson et al. 1986) and extending in vivo persistence from three to six months (Kligman \& Armstrong 1986). Multiple applications, however, are still required for an extended effect. Resoplast (Rofil Medical International, Breda, The Netherlands) is another bovine collagen suspended in a solution of phosphate buffer, sodium chloride, and lidocaine hydrochloride at a concentration of 35 and $65 \mathrm{mg} / \mathrm{ml}$. This dermal filler persists in vivo for a period of three to six months (Naoum and Dasiou-Plakida 2001).

Arteplast, introduced in 1991, is an injectable material composed of microspheres $20-40 \mu \mathrm{m}$ of polymethylmethacrylate (PMMA) suspended in a solution of denatured collagen (Lemperle et al. 1991). Due to issues with foreign body granulomas in reaction to the microspheres, in 1994, Arteplast was replaced by Artecoll (Lemperle et al. 1995) which features larger PMMA microspheres $(30-50 \mu \mathrm{m})$ suspended in Resoplast $(35 \mathrm{mg} / \mathrm{ml})$. The product was subsequently FDA approved in 2006 and marketed as Artefill (Matarasso 2006). Artefill is a permanent filler for the correction of nasolabial folds and the effect of the collagen carrier is sustained by the microspheres through local induced fibrosis which replaces the carrier with host tissue (Lemperle et al. 2010).

\section{Porcine collagen}

Small intestinal submucosa (SIS) is derived from the small intestine of pigs. Following decellularisation the remaining matrix, which is mainly composed of collagen as well as a 
complex mixture of functional and structural molecules, is sterilised and the intact piece of tissue is ready to be used as a replacement scaffold. The benefit of decellularising an intact piece of tissue, whilst retaining the unique 3D ultrastructure, is the low immunogenicity issues which occur when implanting such a scaffold, and the ability of the body to repopulate such a scaffold with its own cells (Badylak et al. 2010). The precise architecture can never be replicated $100 \%$, as even the actions of decellularisation and sterilization affect protein structure, however for matrix-rich tissue replacement this approach is of particular importance, as some elements of the mechanical features of load-bearing tissues can be replicated. There are continuing efforts to use this model to de-cellularise entire organs, and use these 'templet' scaffold architectures to re-seed cells into a more biomimetic environment (Badylak, Taylor, \& Uygun 2010)

Evolence (or Dermicol-P35, ColBar LifeScience, Herzliya, Israel) consists of collagen suspended in a phosphate-buffered saline at a concentration of $35 \mathrm{mg} / \mathrm{ml}$ (Narins et al. 2007). The collagen is derived from pepsin-treated porcine tendons. The purified, telopeptide-poor collagen monomers are polymerised and then cross-linked with D-ribose. The product was FDA approved in 2008 for the treatment of mid to deep facial wrinkles and the cosmetic effect persists up to one year after administration (Narins et al. 2010). The risk of a hypersensitivity response to the product is less than $1 \%$ and the product does not require skin testing prior to use.

\section{Human collagen}

Cosmoderm (Inamed Corporation, Santa Barbara, CA), FDA approved in 2003, consists of collagen extracted and purified from tissue cultures of human foreskin fibroblast (Bauman 2004). Because the product is human derived there is virtually no risk of an immune response and patients therefore do not require pre-procedural skin testing. The collagen is suspended in PBS containing 0.3\% lidocaine hydrochloride and the product is marketed in concentrations of 35 and $65 \mathrm{mg} / \mathrm{ml}$ (Cosmoderm I and II, respectively). Also a longer lasting variant is available in the form of Cosmoplast is cross-linked with glutaraldehyde for greater stability.

Cymetra (Life Cell Corp., Branchburg, NJ) is an intradermal injection product that is composed of cryofractured AlloDerm (Sclafani et al. 2002a). Cymetra is provided as a freezedried powder with an average particle size of $123 \mu \mathrm{m}$ and is reconstituted through the rehydration of $330 \mathrm{mg}$ in $1 \mathrm{ml}$ of $1 \%$ lidocaine hydrochloride. Its effect last longer than Zyplast but shorter than Alloderm, possibly due to a larger surface area.

Autologen (Collagenesis, Inc., Beverly, Mass.) is a dermal matrix dispersion obtained from autologous skin obtained from the patient during previous elective surgery (Fagien and Elson 2001). Dermalogen, from the same company, is a similar product except that the skin is obtained from tissue banks. The dermis is mechanically pulverised and solubilised with chemical modifiers to form a dispersion of predominantly native, type I collagen, traces of types III and VI collagen, elastin, fibronectin, chondroitin sulfate, and other proteoglycans. Autologen and Dermalogen persistence is comparable to Zyplast (Sclafani et al. 2000;Sclafani et al. 2002b). Due to the human origin both products do not cause an immune response and do not require pre-procedural skin testing. The major drawbacks, however, are the requirement of a previous surgical procedure to acquire skin and a processing time of 3 to 4 weeks (Autologen) and the theoretical risk of disease transmission (Dermalogen). Both products are currently not available.

Isologen (Isologen Technologies, Metuchen, NJ) is not a collagen filler but uses autologous fibroblast transplantation to provide collagen at the site of interest. Fibroblasts are obtained 
from a $3 \mathrm{~mm}$ punch biopsy and grown for a period of 2 months to obtain a sufficient number of cells for a clinical effect (Watson et al. 1999).

\section{Methods to control collagen architecture in vivo and in vitro: Engineering collagen conformation: density, direction, diameter}

There are a wide variety of collagen substitutes, as have been documented, however to engineer a functional tissue with collagen, controlling the behaviour and architectural features of collagen in vitro will be necessary. Some of these mechanisms have been inspired by mechanisms in vivo, but the majority have derived from engineering principles derived from our understanding of the protein in question. Here we overview some novel approaches to controlling collagen architecture.

Collagen type I is used for 3D culture of cells, providing a biomimetic environment in which to study cell behaviour (Grinnell and Petroll 2010). Typically collagen scaffolds comprise of collagen hydrogels, which as the name suggests are mainly water. This generally means that the density of such scaffolds is inappropriate for modeling tissue matrix densities. These hydrogels are useful, however, in studying the interactions of cell-matrix, as cells are able to remodel the matrix into which they have been seeded, to orientate collagen fibrils, to control alignment of cells where strain is applied along an axis, and encourage specific behaviours of cells in response to alignment e.g. fusion of single myoblasts to form multi-nucleated fibres (Cheema et al. 2003). During this process the matrix is remodeled, and this tends to result in loss of water from the hydrogel, thus increasing the density of collagen.

Advances have been made to controllably increase the density of collagen scaffolds, with a recent application of controlled load to plastically compress (PC) standard collagen hydrogels to expel excess fluid and increase the collagen density (Brown et al. 2005). Application of this PC technology is very useful for in vitro tissue modeling as cell viability is retained in cells embedded within scaffolds undergoing PC, and the density increase (both for matrix and cells) is controllable and results in densities more biomimetic. At $11 \%$ collagen density, standard PC techniques bring scaffolds to in vivo levels of matrix density, however the mechanical properties of such scaffolds still fall far from those found in tissues. Further methods utilising PC technology have pushed these densities up to $30 \%$ and even higher (Abou-Neel et al. 2006). But what it lacks is the specific architecture for which a multi-disciplined approach to mimicking collagen architecture is required.

Despite the importance of collagen fibril diameter to the material properties of tissues, our basic understanding of its control is poor. Control of fibril diameter is distinct from fibrillogenesis, which is the emergence of the tertiary collagen protein structure.

Fibril modifying molecules, such as collagen types V and IX and proteoglycans such as decorin, are the main suggested mechanisms by which collagen fibril diameter is controlled in vivo, and these elements limit how large fibrils can grow in tissues such as cornea or tendon (Ameye and Young 2002;Ezura et al. 2000;Scott 1984). There is also an emerging understanding of how fibrils diameters can be increased, by using mechanical forces to apply cyclical loading of collagen containing gels, encouraging lateral fusion of fibrils, which is plausible when the quarter stagger patterns of the fibrils of collagen are in perfect register (Figure 1) (Cheema et al. 2007). This 'register' is most commonly identified as the banding pattern seen in transmission electron micrographs of native collagen fibrils. The need for banding pattern registration again lies in the short-range, non-covalent bonds presented between adjacent molecules, which drive fibril polymer formation. The bonding involved 
during this proposed fusion of fibrils is likely to be identical to the ionic and hydrogen bonding thought to stabilise the quarter stagger molecular packing in the original fibril.

Although this appears to be an engineering trick in vitro, it is highly likely that such mechanical forces occur in any new tissue in vivo under load. And importantly, the ability to control collagen fibril diameter without cells shows for the first time that mechanical forces in vivo may help determine fibril diameter and that cell-free engineering of native collagen materials is possible. Using technologies and strategies to manipulate and control fibril diameter will be critical to engineering collagen proteins for suitable use as a scaffold.

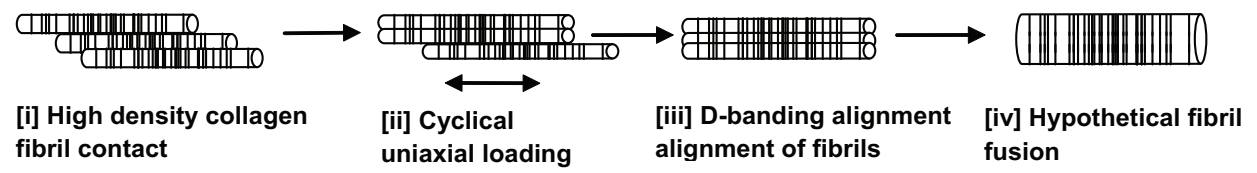

Figure 1a

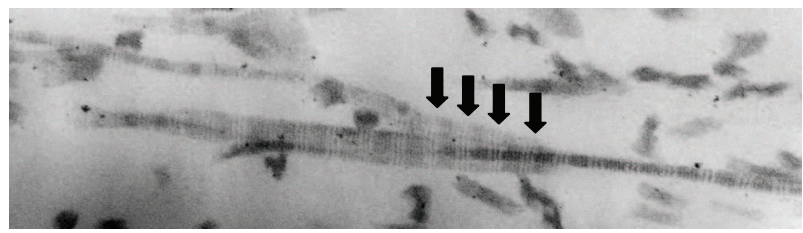

Figure 1b

Fig. 1. a) Hypothesis for the mechanically mediated mechanism for collagen fibril anastomosis. [i] Collagen fibrils in contact. At points of fibril lateral contact there will be very few where adjacent fibrils in 'surface charge' register. [ii] Application of cyclical uniaxial tensile strain inevitably brings a proportion of fibrils into register. [iv] Fibrils in contact and in register will form stable anastomoses, resulting in thicker fibril populations. [v] Bonding for this would comprise non-covalent, ionic, hydrogen and hydrophobic linkages which also drive fibrillogenesis. Figure 1b. Collagen fibrils in Longitudinal section, showing banding pattern register in the parallel elements in a multiple fibril cluster, as the fibril elements appear to anastomose. Arrows indicate alignment of banding pattern between different fibrils, over this length there are three separate fibrils in register, flanked by only one fibril (right) and three fibrils out of register (left) (magnification bar $=700 \mathrm{~nm}$ ). Figure adapted from Cheema et al. 2007

The alignment of collagen fibrils in scaffolds is a critical parameter for control of architectural features. Without mimicking this alignment found in tissues, it is not possible to build a biomimetic tissue. Methods used in vitro to control alignment of collagen type I include magnetic alignment, interstitial directional fluid flow to control alignment and flow of collagen solution through microfluidic chambers during gelation (Elsdale and Bard 1972; Girton et al. 1999;Guo and Kaufman 2007; Lee et al. 2006; Ng and Swartz 2003;Ng and Swartz 2006). Elsdale and Bard were amongst the first groups able to align collagen. By simply setting a gel in a slanted chamber, and allowing interstitial fluid to flow downwards, collagen fibrils were observed to align along this fluid flow (Elsdale \& Bard 1972). Tranquillo and colleagues have applied magnetic field to type I collagen scaffold, during gelation, and found that they collagen fibrils aligned along the plane in which the magnet was aligned (Girton, Dubey, \& Tranquillo 1999).The majority of these alignment strategies have been applied to collagen hydrogels, however it is possible to align collagen fibrils in dense scaffolds using a similar fluid flow mechanism (Kureshi et al. 2010). Recently both the 
magnetic alignment and fluid-flow alignment methods have been applied together to controllable align collagen fibrils (Guo \& Kaufman 2007).

Electro-spinning, which is a method used to spin nano-and micro- diameter fibres into 3D meshes, is cuurently employed as a mechanism to compose 3D scaffolds using collagen and other natural proteins (Matthews et al. 2002). Collagen specifically retains its composition of polypeptide chains and even exhibits superfifical D-Banding of fibrils following the electrospinning process (Jhu et al. 2011). Such electro-spun scaffolds have been employed as tissue engineered substitutes for dermal tissue and muscle reconstruction (Jhu et al. 2011). The electro-spun material is still deficient in some of its mechanical properties, including tensile strength, and the cell-interaction with such materials still requires further investigation.

The methods described within this section will need to be critically used to generate the meso and micro-scale architecture required to mimic tissues. There are limitations to each of these methods and further research into how to finely control collagen protein architecture is required. An example is how to control the bimodal distribution of fibril diameters within native tissues. Currently strategies rely mainly on increasing fibril diameter, for example by application of cyclical load, we are as yet unable to restrict fibril diameter in 3D collagen gels. Even with cyclical loading, we are only able to apply a broad loading regime to all the fibrils, and not select a population to increase, to allow for the typical bi-modal distribution. Further complications arise as cells often need to be embedded within 3D scaffolds as they are being cast, this means that making such engineering parameters cell-friendly will be critical to the ultimate success of an engineered tissue.

\section{Problems with matrix-cell-interaction}

One of the major obstacles in using scaffold materials into which cells are seeded, is the loss of cell directed control of matrix architecture, specifically protein architecture. Culturing cells in 3D collagen hydro-gels allows for cells to interact and remodel the matrix, but there are limitations to how accurately cell-matrix interaction in vivo can be mimicked (Grinnell \& Petroll, 2010). It is difficult to simulate the force applied in vivo as a tissue develops or repairs, often multiple cell types and multiple matrix proteins are involved in the process, and this is time consuming to recapitulate in vitro. By engineering architecture is a speedy manner, we remove the cell-interactive component, and we may also be eliminating some of the cues necessary for cells to also mature and/or differentiate along with the protein architecture. As our models become progressively more tissue like, this interaction will need to be addressed. Cell loading itself has an affect on cell-matrix interaction and matrix remodelling (Cheema et al. 2003). Compliant 3D collagen hydro-gels translate force to cells embedded within the scaffold very well, however as the collagen matrix stiffens and remodels, less force is translated to the embedded cells, primarily due to stress-shielding by the stiffer matrix. Further studies are required to dissect out this iterative process of matrix re-modelling with cell response, and while possible to study in simple single cell type and single matrix cultures in vitro, is much more difficult to decipher in a tissue.

Overarching all of this is the adaptive response of tissues, which renders the tissue able to adapt to changing mechanical requirements, environment, repair etc. In an animal, growth and repair of tissues requires a constant degree of adaptation, which is mainly orchestrated by the resident cells. These cells control protein deposition, and the architecture is then directed by the imposition of mechanical loading by the tissue and resident cells. This iterative process is difficult to define within the tissue, due to the presence of multiple cell 
types, multiple proteins, interaction with surrounding tissues, complex mechanical loading and stress, and variance with age and degree of re-modelling.

Engineering functional collagen-based tissues, whilst trying to emulate all of these processes, and allowing for how they may further re-model such a scaffold is a challenge. Further research into the biological mechanisms controlling tissue architecture will help us develop more successful 3D implants.

\section{Conclusions}

Being the dominant protein of the majority of tissues of the body, the architecture and packing of collagen needs to be controlled is we are to successfully engineer tissues in vitro. There are many currently available collagen scaffold materials, for use in vivo, as replacement skin, tissue fillers and artificial vascular structures, but the best of these have relied upon retaining the original architecture of the collagen from tissues. By understanding how this protein is modified and packed in vivo, by cells, mechanical load and other matrix proteins, we can apply these procedures to predictably control collagen architecture. Without this level of controlled engineering of collagen protein for scaffold manufacture, it is unlikely we will successfully engineer scaffolds with the appropriate mechanical properties, to mimic native tissue mechanics.

There has been a significant drive to engineer the more dominant protein components found within matrix-rich tissues, but controlling the architectural parameters of more minor protein components is also critical, and getting these processes to work in synchrony remains a challenge. This control over tissue architecture needs to be done without compromising on cell viability, cell action and appropriate cell differentiation.

Using native proteins has both benefits, due to the biomimicry of protein motifs and structural elements, and pitfalls compared to manufacturing synthetic polymers as scaffold materials. Synthetic polymers are man-made and engineered to precisely fulfil the required mechanical properties of any implant, but they lack the native cell-attachment motifs. Controlling the architecture, in vitro, of native proteins, including predominantly collagen, holds the key to the successful engineering of biomimetic, native protein based implants and constructs.

\section{References}

Abou-Neel, E.A., Cheema, U., Knowles, J.C., Brown, R.A., \& Nazhat, S.N. 2006. Use of multiple unconfined compression for fine control of collagen gel scaffold density and mechanical properties. Soft Matter, 2, 986-992

Amani, H., Dougherty, W.R., \& Blome-Eberwein, S. 2006. Use of Transcyte and dermabrasion to treat burns reduces length of stay in burns of all size and etiology. Burns, 32, (7) 828-832 available from: PM:16997480

Ameye, L. \& Young, M.F. 2002. Mice deficient in small leucine-rich proteoglycans: novel in vivo models for osteoporosis, osteoarthritis, Ehlers-Danlos syndrome, muscular dystrophy, and corneal diseases. Glycobiology, 12, (9) 107R-16R

Badylak, S.F., Taylor, D., \& Uygun, K. 2010. Whole-Organ Tissue Engineering: Decellularization and Recellularization of Three-Dimensional Matrix Scaffolds. Annu.Rev.Biomed Eng available from: PM:21417722

Bauman, L. 2004. CosmoDerm/CosmoPlast (human bioengineered collagen) for the aging face. Facial.Plast.Surg., 20, (2) 125-128 available from: PM:15643578 
Bell, E., Ehrlich, H.P., Buttle, D.J., \& Nakatsuji, T. 1981a. Living tissue formed in vitro and accepted as skin-equivalent tissue of full thickness. Science, 211, (4486) 1052-1054 available from: PM:7008197

Bell, E., Ehrlich, H.P., Sher, S., Merrill, C., Sarber, R., Hull, B., Nakatsuji, T., Church, D., \& Buttle, D.J. 1981b. Development and use of a living skin equivalent. Plast.Reconstr.Surg., 67, (3) 386-392 available from: PM:7232576

Brown, R.A., Wiseman, M., Chuo, C.B., Cheema, U., \& Nazhat, S.N. 2005. Ultrarapid Engineering of Biomimetic Materials and Tissues: Fabrication of Nano- and Microstructures by Plastic Compression. Adv Funct Mat, 15, (11) 1762-70

Burke, J.F., Yannas, I.V., Quinby, W.C., Jr., Bondoc, C.C., \& Jung, W.K. 1981. Successful use of a physiologically acceptable artificial skin in the treatment of extensive burn injury. Ann Surg., 194, (4) 413-428 available from: PM:6792993

Cheema, U., Chuo, C.B., Sarathchandra, P., Nazhat, S.N., \& Brown, R.A. 2007. Engineering Functional Collagen Scaffolds: Cyclical loading increases material strength and fibril aggregation'. Adv Funct Mat, 17, 2426-31

Cheema, U., Yang, S.Y., Mudera, V., Goldspink, G., \& Brown, R.A. 2003. 3-D In Vitro Model of Early Skeletal Muscle Development. Cell Motil Cytoskeleton, 54, 226-236

Cooper, M.L., Hansbrough, J.F., Spielvogel, R.L., Cohen, R., Bartel, R.L., \& Naughton, G. 1991. In vivo optimization of a living dermal substitute employing cultured human fibroblasts on a biodegradable polyglycolic acid or polyglactin mesh. Biomaterials, 12, (2) 243-248 available from: PM:1652296

Eisenberg, M. \& Llewelyn, D. 1998. Surgical management of hands in children with recessive dystrophic epidermolysis bullosa: use of allogeneic composite cultured skin grafts. Br.J Plast.Surg., 51, (8) 608-613 available from: PM:10209464

Elsdale, T. \& Bard, J. 1972. Collagen substrata for studies on cell behavior. J Cell Biol, 54, (3) 626-37

Ezura, Y., Chakravarti, S., Oldberg, A., Chervoneva, I., \& Birk, D.E. 2000. Differential expression of lumican and fibromodulin regulate collagen fibrillogenesis in developing mouse tendons. J Cell Biol, 151, (4) 779-88

Fagien, S. \& Elson, M.L. 2001. Facial soft-tissue augmentation with allogeneic human tissue collagen matrix (Dermalogen and Dermaplant). Clin.Plast.Surg., 28, (1) 63-81 available from: PM:11248870

Falanga, V. 2005. Wound healing and its impairment in the diabetic foot. Lancet, 366, (9498) 1736-1743 available from: PM:16291068

Girton, T.S., Dubey, N., \& Tranquillo, R.T. 1999. Magnetic-induced alignment of collagen fibrils in tissue equivalents. Methods Mol Med, 18, 67-73

Griffiths, M., Ojeh, N., Livingstone, R., Price, R., \& Navsaria, H. 2004. Survival of Apligraf in acute human wounds. Tissue Eng, 10, (7-8) 1180-1195 available from: PM:15363174

Grinnell, F. \& Petroll, W.M. 2010. Cell motility and mechanics in three-dimensional collagen matrices. Annu.Rev.Cell Dev.Biol, 26, 335-361 available from: PM:19575667

Guo, C. \& Kaufman, L.J. 2007. Flow and magnetic field induced collagen alignment. Biomaterials, 28, (6) 1105-1114 available from: PM:17112582

Hansbrough, J.F., Morgan, J., Greenleaf, G., \& Underwood, J. 1994. Development of a temporary living skin replacement composed of human neonatal fibroblasts cultured in Biobrane, a synthetic dressing material. Surgery, 115, (5) 633-644 available from: PM:8178264

Heimbach, D., Luterman, A., Burke, J., Cram, A., Herndon, D., Hunt, J., Jordan, M., McManus, W., Solem, L., Warden, G., \& . 1988. Artificial dermis for major burns. A multi-center randomized clinical trial. Ann Surg., 208, (3) 313-320 available from: PM:3048216 
Jha, B.J. Ayres, C.E. Bowman, J.R. Telemeco, T.A. Sell, S.A. Bowlin, G.L. and SimpsoN, D.E. 2011. Electrospun Collagen: A Tissue Engineering Scaffold with Unique Functional Properties in a Wide Variety of Applications. Journal of Nanomaterials, vol. 2011, Article ID 348268. doi:10.1155/2011/348268

Kligman, A.M. \& Armstrong, R.C. 1986. Histologic response to intradermal Zyderm and Zyplast (glutaraldehyde cross-linked) collagen in humans. J Dermatol.Surg.Oncol., 12, (4) 351-357 available from: PM:3082955

Knapp, T.R., Luck, E., \& Daniels, J.R. 1977. Behavior of solubilized collagen as a bioimplant. J Surg.Res., 23, (2) 96-105 available from: PM:886847

Kumar, R.J., Kimble, R.M., Boots, R., \& Pegg, S.P. 2004. Treatment of partial-thickness burns: a prospective, randomized trial using Transcyte. ANZ.J Surg., 74, (8) 622-626 available from: PM:15315558

Kureshi, A., Cheema, U., Alekseeva, T.A., Cambrey, A., \& Brown, R.A. 2010. Alignment hierarchies: engineering architecture from the nanometre to the micrometre scale. $J$ $R$ Soc Interface, 6, S107-16

Lee, P., Lin, R., Moon, J., \& Lee, L.P. 2006. Microfluidic alignment of collagen fibers for in vitro cell culture. Biomed Microdevices, 8, 35-41

Lemperle, G., Hazan-Gauthier, N., \& Lemperle, M. 1995. PMMA microspheres (Artecoll) for skin and soft-tissue augmentation. Part II: Clinical investigations. Plast.Reconstr.Surg., 96, (3) 627-634 available from: PM:7638287

Lemperle, G., Knapp, T.R., Sadick, N.S., \& Lemperle, S.M. 2010. ArteFill permanent injectable for soft tissue augmentation: I. Mechanism of action and injection techniques. Aesthetic Plast.Surg., 34, (3) 264-272

Lemperle, G., Ott, H., Charrier, U., Hecker, J., \& Lemperle, M. 1991. PMMA microspheres for intradermal implantation: Part I. Animal research. Ann Plast.Surg., 26, (1) 57-63

Marston, W.A., Hanft, J., Norwood, P., \& Pollak, R. 2003. The efficacy and safety of Dermagraft in improving the healing of chronic diabetic foot ulcers: results of a prospective randomized trial. Diabetes Care, 26, (6) 1701-1705

Matarasso, S.L. 2006. The use of injectable collagens for aesthetic rejuvenation. Semin.Cutan.Med Surg., 25, (3) 151-157

Matthews,J.A. WJ. G.E. Matthews, A. Wnek, G.E. Simpson, D.G. and G. L. Bowlin. 2002 Electrospinning of collagen nanofibers. Biomacromolecules, vol. 3, no. 2, pp. 232-238

McPherson, J.M., Sawamura, S., \& Armstrong, R. 1986. An examination of the biologic response to injectable, glutaraldehyde cross-linked collagen implants. J Biomed Mater.Res., 20, (1) 93-107 available from: PM:3949825

Michaeli, D. \& McPherson, M. 1990. Immunologic study of artificial skin used in the treatment of thermal injuries. J Burn Care Rehabil., 11, (1) 21-26 available from: PM:2107179

Naoum, C. \& Dasiou-Plakida, D. 2001. Dermal filler materials and botulin toxin. Int.J Dermatol., 40, (10) 609-621 available from: PM:11737419

Narins, R.S., Brandt, F.S., Lorenc, Z.P., Maas, C.S., Monheit, G.D., Smith, S.R., \& McIntyre, S. 2007. A randomized, multicenter study of the safety and efficacy of Dermicol-P35 and non-animal-stabilized hyaluronic acid gel for the correction of nasolabial folds. Dermatol.Surg., 33 Suppl 2, S213-S221 available from: PM:18086061

Narins, R.S., Coleman, W.P., III, Rohrich, R., Monheit, G., Glogau, R., Brandt, F., Bruce, S., Colen, L., Dayan, S., Jackson, I., Maas, C., Rivkin, A., Sclafani, A., \& Spivak, J.C. 2010. 12-Month controlled study in the United States of the safety and efficacy of a permanent $2.5 \%$ polyacrylamide hydrogel soft-tissue filler. Dermatol.Surg., $36 \mathrm{Suppl}$ 3, 1819-1829 available from: PM:20969659 
$\mathrm{Ng}$, C.P. \& Swartz, M.A. 2003. Fibroblast alignment under interstitial fluid flow using a novel 3-D tissue culture model. Am J Physiol-Heart C, 284, H1771-H1777

$\mathrm{Ng}$, C.P. \& Swartz, M.A. 2006. Mechanisms of interstitial flow-induced remodeling of fibroblast-collagen cultures. Ann Biomed Eng, 34, 446-454

Nguyen, D.Q., Potokar, T.S., \& Price, P. 2010. An objective long-term evaluation of Integra (a dermal skin substitute) and split thickness skin grafts, in acute burns and reconstructive surgery. Burns, 36, (1) 23-28 available from: PM:19864070

Omar, A.A., Mavor, A.I., Jones, A.M., \& Homer-Vanniasinkam, S. 2004. Treatment of venous leg ulcers with Dermagraft. Eur.J Vasc.Endovasc.Surg., 27, (6) 666-672 available from: PM:15121121

Prystowsky, J.H., Siegel, D.M., \& Ascherman, J.A. 2001. Artificial skin for closure and healing of wounds created by skin cancer excisions. Dermatol.Surg., 27, (7) 648-653 available from: PM:11442617

Sclafani, A.P., Romo, T., III, \& Jacono, A.A. 2002a. Rejuvenation of the aging lip with an injectable acellular dermal graft (Cymetra). Arch.Facial.Plast.Surg., 4, (4) 252-257 available from: PM:12437432

Sclafani, A.P., Romo, T., III, Parker, A., McCormick, S.A., Cocker, R., \& Jacono, A. 2000. Autologous collagen dispersion (Autologen) as a dermal filler: clinical observations and histologic findings. Arch.Facial.Plast.Surg., 2, (1) 48-52 available from: PM:10925424

Sclafani, A.P., Romo, T., III, Parker, A., McCormick, S.A., Cocker, R., \& Jacono, A. 2002b. Homologous collagen dispersion (dermalogen) as a dermal filler: persistence and histology compared with bovine collagen. Ann Plast.Surg., 49, (2) 181-188 available from: PM:12187346

Scott, J.E. 1984. The periphery of the developing collagen fibril. Biochem.J., 195, 229-33

Smith, J.W. 1960. Collagen fibre patterns in mammalian bone. J Anat, 94, (3) 329-44

Stern, R., McPherson, M., \& Longaker, M.T. 1990. Histologic study of artificial skin used in the treatment of full-thickness thermal injury. J Burn Care Rehabil., 11, (1) 7-13 available from: PM:2179224

Still, J., Glat, P., Silverstein, P., Griswold, J., \& Mozingo, D. 2003. The use of a collagen sponge/living cell composite material to treat donor sites in burn patients. Burns, 29, (8) 837-841 available from: PM:14636761

Veves, A., Falanga, V., Armstrong, D.G., \& Sabolinski, M.L. 2001. Graftskin, a human skin equivalent, is effective in the management of noninfected neuropathic diabetic foot ulcers: a prospective randomized multicenter clinical trial. Diabetes Care, 24, (2) 290295 available from: PM:11213881

Wainwright, D., Madden, M., Luterman, A., Hunt, J., Monafo, W., Heimbach, D., Kagan, R., Sittig, K., Dimick, A., \& Herndon, D. 1996. Clinical evaluation of an acellular allograft dermal matrix in full-thickness burns. J Burn Care Rehabil., 17, (2) 124-136 available from: PM:8675502

Watson, D., Keller, G.S., Lacombe, V., Fodor, P.B., Rawnsley, J., \& Lask, G.P. 1999. Autologous fibroblasts for treatment of facial rhytids and dermal depressions. A pilot study. Arch.Facial.Plast.Surg., 1, (3) 165-170 available from: PM:10937098

Wilkins, L.M., Watson, S.R., Prosky, S.J., Meunier, S.F., \& Parenteau, N.L. 1994. Development of a bilayered living skin construct for clinical applications. Biotechnol.Bioeng., 43, (8) 747-756 available from: PM:18615798

Yannas, I.V., Burke, J.F., Warpehoski, M., Stasikelis, P., Skrabut, E.M., Orgill, D., \& Giard, D.J. 1981. Prompt, long-term functional replacement of skin. Trans.Am Soc Artif.Intern.Organs, 27, 19-23 available from: PM:7036496 


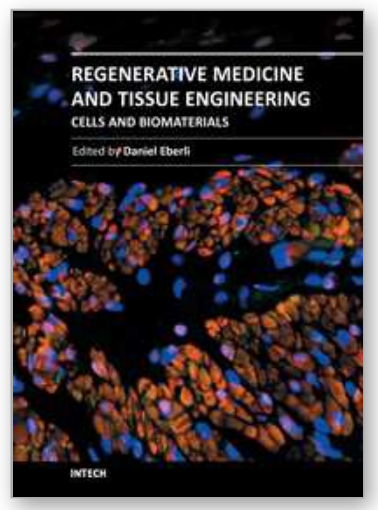

\author{
Regenerative Medicine and Tissue Engineering - Cells and \\ Biomaterials \\ Edited by Prof. Daniel Eberli
}

ISBN 978-953-307-663-8

Hard cover, 588 pages

Publisher InTech

Published online 29, August, 2011

Published in print edition August, 2011

Tissue Engineering may offer new treatment alternatives for organ replacement or repair deteriorated organs. Among the clinical applications of Tissue Engineering are the production of artificial skin for burn patients, tissue engineered trachea, cartilage for knee-replacement procedures, urinary bladder replacement, urethra substitutes and cellular therapies for the treatment of urinary incontinence. The Tissue Engineering approach has major advantages over traditional organ transplantation and circumvents the problem of organ shortage. Tissues reconstructed from readily available biopsy material induce only minimal or no immunogenicity when reimplanted in the patient. This book is aimed at anyone interested in the application of Tissue Engineering in different organ systems. It offers insights into a wide variety of strategies applying the principles of Tissue Engineering to tissue and organ regeneration.

\title{
How to reference
}

In order to correctly reference this scholarly work, feel free to copy and paste the following:

Umber Cheema, Michael Ananta and Vivek Mudera (2011). Collagen: Applications of a Natural Polymer in Regenerative Medicine, Regenerative Medicine and Tissue Engineering - Cells and Biomaterials, Prof. Daniel Eberli (Ed.), ISBN: 978-953-307-663-8, InTech, Available from:

http://www.intechopen.com/books/regenerative-medicine-and-tissue-engineering-cells-andbiomaterials/collagen-applications-of-a-natural-polymer-in-regenerative-medicine

\section{INTECH}

open science | open minds

\section{InTech Europe}

University Campus STeP Ri

Slavka Krautzeka 83/A

51000 Rijeka, Croatia

Phone: +385 (51) 770447

Fax: +385 (51) 686166

www.intechopen.com

\section{InTech China}

Unit 405, Office Block, Hotel Equatorial Shanghai

No.65, Yan An Road (West), Shanghai, 200040, China

中国上海市延安西路65号上海国际贵都大饭店办公楼 405 单元

Phone: +86-21-62489820

Fax: $+86-21-62489821$ 
(C) 2011 The Author(s). Licensee IntechOpen. This chapter is distributed under the terms of the Creative Commons Attribution-NonCommercialShareAlike-3.0 License, which permits use, distribution and reproduction for non-commercial purposes, provided the original is properly cited and derivative works building on this content are distributed under the same license. 